\title{
APLICAÇÃO DE CARVÃO ATIVADO DE BAGAÇO DE CANA-DE-AÇÚCAR NA ADSORÇÃO DE Cd(II) E Cu(II)
}

\author{
M. B. ABREU ${ }^{1 *}$, J. R. ANDRADE ${ }^{2}$, F. R. B. TURBIANI ${ }^{1}$, M. L. GIMENES ${ }^{2}$, N. R. C. \\ FERNANDES-MACHADO ${ }^{2}$, F. L. SEIXAS ${ }^{1,2}$ \\ ${ }^{1}$ Universidade Tecnológica Federal do Paraná, Departamento de Tecnologia em Processos \\ Químicos \\ ${ }^{2}$ Universidade Estadual de Maringá, Departamento de Engenharia Química \\ e-mail: marcela.abreu@ifpr.edu.br
}

\begin{abstract}
RESUMO
O presente trabalho avalia a remoção de íons metálicos presentes em efluentes sintéticos por empregando a adsorção. Os metais pesados avaliados foram cádmio e cobre, e o adsorvente utilizado foi carvão ativado de bagaço de cana-de-açúcar, produzido por ativação química com cloreto de zinco. $\mathrm{O}$ pH determinado para carvão ativado de bagaço foi de 4,62, caracterizando-o como um material de propriedade ácida e apto à adsorção de cátions metálicos. Estudos de adsorção foram conduzidos em sistemas estáticos variando os parâmetros: tempo de contato, $\mathrm{pH}$, concentração inicial. O tempo de equilíbrio obtido pelos testes cinéticos foi de 48 horas. Em concentração inicial de $150 \mathrm{mg} . \mathrm{L}^{-1}$, a capacidade de adsorção no equilíbrio foi $30,22 \mathrm{e} 27,88 \mathrm{mg} \cdot \mathrm{g}^{-1} \mathrm{para} \mathrm{Cd}^{2+} \mathrm{e}$ $\mathrm{Cu}^{2+}$, respectivamente. $\mathrm{O} \mathrm{pH}$ ótimo para adsorção de $\mathrm{Cd}^{2+}$ e $\mathrm{Cu}^{2+}$ foi 4 e 6 , respectivamente. Os modelos de isotermas de Langmuir e Freundlich foram aplicados. $\mathrm{O}$ modelo de Langmuir foi o que ajustou melhor os dados de equilíbrio de $\mathrm{Cd}^{2+}$. A capacidade máxima de adsorção de $\mathrm{Cd}^{2+}$ a $30{ }^{\circ} \mathrm{C}$ foi $106,383 \mathrm{mg} \cdot \mathrm{g}^{-1}$. Para a isoterma de $\mathrm{Cu}^{2+}$, os ajustes dos modelos foram insatisfatórios. Testes cinéticos empregando-se carvão ativado comercial granular foram realizados para comparação e comprovação da eficácia do adsorvente alternativo estudado. A capacidade de adsorção do carvão ativado de bagaço de cana-de-açúcar se mostrou superior à do comercial na remoção de $\mathrm{Cu}^{2+}$. Para a remoção de $\mathrm{Cd}^{2+}$ os carvões apresentaram capacidades próximas.
\end{abstract}

\section{INTRODUÇÃO}

A poluição dos recursos hídricos é um grave problema enfrentado pela sociedade, pois a água é indispensável à vida e sua contaminação resulta em graves problemas de desequilíbrio ecológico e da saúde, além de afetar diretamente a produção de alimentos. Dentre os vários contaminantes orgânicos e inorgânicos, os metais pesados são de natureza altamente tóxica e carcinogênica. Sendo assim, a presença de metais pesados no ambiente aquático é preocupante, mesmo em baixas concentrações (GUPTA e ALI, 2004).

O metal cobre é lançado especialmente pelas indústrias de mineração, fertilizantes, refino de petróleo, tintas e pigmentos, siderurgias, fundições, galvanoplastia e equipamentos elétricos. $\mathrm{O}$ cobre é um elemento essencial, porém em doses agudas provoca distúrbios metabólicos. $\mathrm{O}$ envenenamento crônico por este metal causa anemia hemolítica, anormalidades neurológicas e opacidade da córnea (MOHAN, PITTMAN JR. e STEELE, 2006). 
Em relação ao cádmio, além das indústrias de mineração, fertilizantes fosfatados, galvanoplastia, tintas e pigmentos, a indústria de pilhas alcalinas e ligas metálicas também geram quantidades significativas de efluentes líquidos contendo esse metal (JAIN, GARG e KADIRVELU, 2013). O cádmio é muito tóxico e pode causar sérios danos aos rins e ossos (MOHAN, PITTMAN JR. e STEELE, 2006).

Várias técnicas têm sido empregadas para o tratamento de efluentes contendo metais pesados, tais como: precipitação química, adsorção, eletrólise, troca-iônica e osmose reversa (ÜÇCER et al., 2005). O método de adsorção, entretanto, é vantajoso ao poder ser empregado independente da concentração do metal em solução, ser de fácil operação e de baixo custo de investimento. Assim, a adsorção é tida como uma ótima alternativa para o tratamento de efluentes contendo metais pesados.

A IUPAC (International Union of Pure and Applied Chemistry) define a adsorção como o enriquecimento de um ou mais componentes sobre a camada interfacial de um material adsorvente. O material no estado adsorvido é chamado de adsorbato, enquanto aquele que ainda pode ser adsorvido da fase fluida é chamado de adsorvível (SING et al., 1985). Há mais de três décadas, carvão ativado tem sido usado frequentemente na adsorção de íons metálicos de efluentes. Porém, o carvão ativado disponível comercialmente é caro, o que tem incentivado a busca por adsorventes alternativos, como carvão ativado produzido a partir de materiais residuais (GUPTA e ALI, 2004).

O Brasil é o maior produtor mundial de cana-de-açúcar, tanto para indústrias de álcool quanto de açúcar. De acordo com o levantamento da Companhia Nacional de Abastecimento (CONAB), o Brasil produziu aproximadamente 634,8 milhões de toneladas de cana na safra 2014/2015 (BRASIL, 2015). Em média, $280 \mathrm{~kg}$ de bagaço de cana contendo $50 \%$ de umidade são produzidos por tonelada de cana processada. Nestas indústrias, o bagaço é queimado para produzir energia para usinas de açúcar, mas a quantidade restante ainda é significativa (GURGEL, DE FREITAS e GIL, 2008). Alternativas rentáveis de emprego desse subproduto são de grande interesse, especialmente para a agroindústria brasileira.

Experimentos prévios mostraram que o carvão produzido a partir de bagaço de canade-açúcar e ativado quimicamente com cloreto de zinco $\left(\mathrm{ZnCl}_{2}\right)$, referenciado neste estudo como CA Bagaço, apresenta boa distribuição de poros, elevada área superficial e tem capacidade de adsorção. Se empregado como adsorvente alternativo, esse carvão pode reduzir ainda mais o custo de operação dos processos de adsorção.

O presente trabalho avalia a remoção dos metais cádmio e cobre de soluções aquosas através do processo de adsorção empregando carvão ativado de bagaço de cana-de-açúcar. A eficácia desse adsorvente foi comparada àquela obtida empregando-se carvão ativado comercial granular da marca Carbomafra (CA Comercial).

\section{MATERIAIS E MÉTODOS}

\subsection{Preparação do Carvão Ativado}

Foi utilizado bagaço de cana-de-açúcar cedido pela usina Santa Terezinha, localizada na cidade de Iguatemi (PR). O carvão produzido a partir de bagaço de cana-deaçúcar foi preparado segundo a metodologia proposta por Schettino Jr. (2004), com algumas modificações. Inicialmente o bagaço de cana foi carbonizado em mufla a $500{ }^{\circ} \mathrm{C}$, por 2 horas. Posteriormente, a amostra carbonizada foi ativada por impregnação com solução de $\mathrm{ZnCl}_{2}(18,4 \mathrm{M})$ na razão mássica de 1:3. Após este procedimento a mistura foi submetida à ativação em um reator de inox. Foi utilizada uma rampa de aquecimento de $5{ }^{\circ} \mathrm{C} \mathrm{min}^{-1}$, inicialmente até $400{ }^{\circ} \mathrm{C}$, patamar 


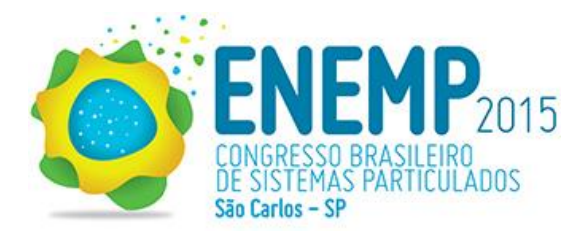

em que a amostra permaneceu por $1 \mathrm{~h}$ para a desidratação da mistura, e posteriormente até $600{ }^{\circ} \mathrm{C}$, onde permaneceu por mais $1 \mathrm{~h}$. Finalmente, a amostra foi lavada com água destilada, filtrada e seca em estufa a $180^{\circ} \mathrm{C}$ por $24 \mathrm{~h}$.

\subsection{Caracterização do pH do Carvão Ativado}

$\mathrm{O}$ pH do CA Bagaço foi determinado usando a norma ASTM D3838-80, descrita por Valix, Cheung e McKay (2004). Foram aquecidos $0,5 \mathrm{~g}$ de carvão ativado em $20 \mathrm{~mL}$ de água destilada. Após sua fervura, a suspensão permaneceu em chapa aquecedora por 15 minutos. Em seguida, a suspensão foi filtrada em papel de filtro qualitativo e posteriormente foi medido $\mathrm{o} \mathrm{pH}$ da solução obtida, com auxílio de pHmetro digital (Instrutherm PH-2000). O pH do CA Comercial também foi avaliado.

\subsection{Preparação dos Efluentes Sintéticos}

Foram preparadas soluções estoque dos íons $\mathrm{Cd}^{2+}$ e $\mathrm{Cu}^{2+}$ na concentração $150 \mathrm{mg} . \mathrm{L}^{-1}$ a partir dos compostos $\mathrm{CdCl}_{2} 2,5 \mathrm{H}_{2} \mathrm{O}$ e de $\mathrm{Cu}\left(\mathrm{NO}_{3}\right)_{2} \cdot 3 \mathrm{H}_{2} \mathrm{O}$, respectivamente.

\subsection{Estudos de Adsorção}

Testes de adsorção de $\mathrm{Cd}^{2+}$ e $\mathrm{Cu}^{2+}$ foram realizados em batelada. Fatores incluindo tempo de contato, $\mathrm{pH}$, e concentração inicial foram avaliados.

\subsubsection{Estudos Cinéticos}

Testes cinéticos com cada íon metálico foram realizados para determinar o tempo de equilíbrio de adsorção. Volumes de $20 \mathrm{~mL}$ das soluções de $\mathrm{Cu}^{2+}$ ou $\mathrm{Cd}^{2+}$ na concentração de $150 \mathrm{mg} . \mathrm{L}^{-1}$ foram adicionados juntamente com 0,05 g de CA Bagaço em uma série de frascos de Erlenmeyer. Antes dos testes o pH das soluções foi ajustado para 6, valor no qual Karnitz et al. (2009) obtiveram boa capacidade de remoção para ambos os íons $\mathrm{Cd}^{2+}$ e $\mathrm{Cu}^{2+}$. Para o ajuste, foram utilizadas soluções de hidróxido de sódio $(\mathrm{NaOH})$ ou ácido clorídrico $(\mathrm{HCl}), 0,1 \quad \mathrm{M}$. Após o processo de adsorção, os $\mathrm{pH}$ finais das soluções foram medidos.

O material adsorvente e o efluente sintético foram deixados em contato em banho termostático a $30^{\circ} \mathrm{C}$, sob agitação lenta e constante. Frascos foram retirados para análise em intervalos de tempo prédeterminados: 10, 20, 30, 40, 50, 60, 3600, 1.440 e $2.880 \mathrm{~min}$. As suspensões dos frascos foram filtradas e as concentrações residuais dos metais presentes nos efluentes sintéticos após o processo de adsorção foram determinadas por absorção atômica com equipamento Spectraa- 50B. Uma curva de calibração da absorção foi construída para o $\mathrm{Cu}^{2+}$ no intervalo de 5 a 20 ppm $(5,10,15$ e $20 \mathrm{ppm}$ ), utilizando-se um comprimento de onda de 327,4 nm nas análises. Já para a análise de $\mathrm{Cd}^{2+}$, o comprimento de onda foi de $228,8 \mathrm{~nm}$ e a curva de calibração foi construída no intervalo de 0,5 a 3 ppm $(0,5 ; 1$; 2 e 3 ppm).

A quantidade de íon metálico adsorvido em um tempo $t\left(q_{t}\right)$, foi calculada através da Equação 1 (TEOH, KHAN e CHOONG, 2013).:

$q_{t}=\frac{V\left(C_{0}-C_{t}\right)}{m}$

em que $C_{0}$ é a concentração inicial da solução de íons metálicos (150 mg. $\left.\mathrm{L}^{-1}\right), C_{t}$ é a concentração da fase líquida no tempo $t, V$ é o volume de solução utilizada no ensaio (20 $\mathrm{mL}$ ), e $m$ corresponde à massa do adsorvente utilizada no teste $(0,05 \mathrm{~g})$.

Para efeito de comparação, também foram realizados testes cinéticos usando como adsorvente o CA Comercial.

\subsubsection{Efeito do pH na Adsorção}

A remoção de íons metálicos de soluções aquosas por adsorção é dependente do pH da solução, já que este parâmetro afeta 
o grau de ionização das espécies e as características da superfície do adsorvente (KARNITZ et al., 2009).

$\mathrm{O}$ efeito do $\mathrm{pH}$ na remoção dos íons metálicos foi investigado nas mesmas condições propostas para os testes cinéticos, cujos tempos de equilíbrio determinados foram empregados. Todos os experimentos foram conduzidos em valores iniciais de $\mathrm{pH}$ inferiores aos do começo do processo de hidrólise e precipitação metálica, estimados como $\mathrm{pH}>6,3$ para $\mathrm{Cu}(\mathrm{OH})_{2}$ e $\mathrm{pH} 8,2$ para $\mathrm{Cd}(\mathrm{OH})_{2}$ (MOHAN, PITTMAN JR. e STEELE, 2006). Os valores de $\mathrm{pH}$ iniciais foram ajustados pela adição tanto de $\mathrm{NaOH}$ (0,1 M) quanto de $\mathrm{HCl}(0,1 \mathrm{M})$.

Em dado $\mathrm{pH}$, a quantidade de $\mathrm{Cu}^{2+}$ ou $\mathrm{Cd}^{2+}$ adsorvida no equilíbrio $\left(q_{e}\right)$ é fornecida pela Equação 2:

$q_{e}=\frac{V\left(C_{0}-C_{e}\right)}{m}$

A Equação 2 é idêntica à Equação 1, exceto pela substituição de $C_{t}$ por $C_{e}$. Aqui, $C_{e}$ é a concentração de íons na fase líquida no equilíbrio.

\subsubsection{Isotermas de Adsorção}

No estado de equilíbrio, a quantidade adsorvida por grama do adsorvente é função apenas da pressão final e da temperatura. Quando a pressão do sistema é variada e a temperatura é mantida constante, a relação entre a quantidade adsorvida e a pressão é conhecida como isoterma de adsorção. Alternativamente, no lugar da pressão, podem ser usadas unidades de concentração, tal como a concentração mássica do adsorvível na fase fluida em equilíbrio (BRUNAUER, 1943).

Para a obtenção das isotermas, foram colocadas em contato com o adsorvente as soluções contendo $\mathrm{Cu}^{2+}$ ou $\mathrm{Cd}^{2+}$ nas seguintes concentrações iniciais: 25, 50, 75, 100, 125 e $150 \mathrm{mg} . \mathrm{L}^{-1}$. Nesses testes de adsorção, empregou-se o tempo de equilíbrio determinado nos testes cinéticos, bem como o pH em que houve maior adsorção de metal por grama de carvão ativado. Ao final de cada experimento foi possível calcular a quantidade de íons adsorvida no equilíbrio $\left(q_{e}\right)$ pela Equação 2.

\section{RESULTADOS E DISCUSSÃO}

\subsection{Características do Carvão Ativado}

Os valores encontrados para o $\mathrm{pH}$ do CA Bagaço e também para o CA Comercial foram 4,62 e 6,34, respectivamente. Portanto, ambos os carvões apresentaram características ácidas, portanto, têm capacidade de adsorver prótons.

Os carvões ácidos apresentam complexos oxigenados em sua superfície. Esses complexos provêm do material de origem ou da oxidação durante a ativação ou ainda do período de estocagem após ativação (SUZUKI, 1990). Desta forma, o mecanismo de adsorção em carvões ativados também pode ser explicado baseando-se em modelos de troca iônica. $\mathrm{Na}$ superfície do carvão ativado (S), um complexo carbono-oxigênio se liga aos íons metálicos deslocando prótons da superfície. Este modelo de troca iônica é ilustrado pelas Equações 3 e 4 (KADIRVELU e NAMASIVAYAM, 2003).

$$
\begin{aligned}
& 2 \mathrm{~S}-\mathrm{COH}+\mathrm{M}^{+} \leftrightarrow \mathrm{S}-(\mathrm{CO})_{2} \mathrm{M}^{+}+2 \mathrm{H}^{+} \\
& \mathrm{S}-\mathrm{COH}_{2}{ }^{2+}+\mathrm{M}^{+} \leftrightarrow \mathrm{S}-\mathrm{COM}^{2+}+2 \mathrm{H}^{+}
\end{aligned}
$$

\subsection{Testes Cinéticos}

As curvas cinéticas relacionam a quantidade de íons adsorvida por unidade de massa de adsorvente com o tempo. A Figura 1 apresenta as curvas cinéticas para os metais cádmio e cobre, empregando-se como adsorventes CA Bagaço e CA Comercial. 
Figura 1 - Testes cinéticos de adsorção de: (a) $\mathrm{Cd}^{2+}$ e (b) $\mathrm{Cu}^{2+}$, empregando CA Bagaço e CA Comercial
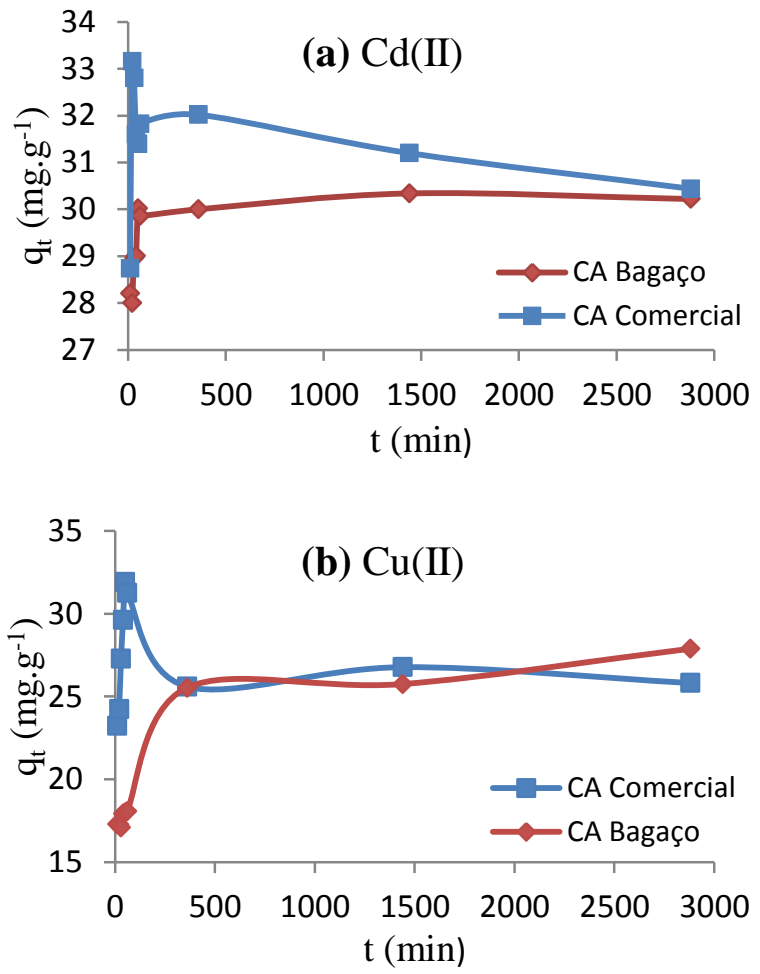

Fonte: Abreu (2013)

Em se tratando do CA Bagaço, observando a Figura 1(a), pode-se considerar $24 \mathrm{~h}$ (1.440 $\mathrm{min})$ como o tempo em que a quantidade de $\mathrm{Cd}^{2+}$ adsorvido por grama de adsorvente entra em equilíbrio. Na Figura 1(b), no intervalo de tempo entre 6 e 24h (360 a $1.440 \mathrm{~min}$ ) a quantidade de $\mathrm{Cu}^{2+}$ adsorvida por grama de carvão ativado parece entrar em equilíbrio. Porém, analisando essa quantidade até as $48 \mathrm{~h}$ ( $2.880 \mathrm{~min})$ tem-se que ela ainda aumenta com o decorrer do ensaio. Admitindo então como tempo equilíbrio $48 \mathrm{~h}$, testes cinéticos para $\mathrm{Cd}^{2+}$ e $\mathrm{Cu}^{2+}$ foram realizados empregando-se o CA Comercial.

A quantidade adsorvida de $\mathrm{Cd}^{2+}$ após 48 h empregando-se CA Bagaço foi de 30,22 $\mathrm{mg} \cdot \mathrm{g}^{-1}$, quantidade próxima à obtida quando utilizado o CA Comercial $\left(30,44 \mathrm{mg}^{-\mathrm{g}^{-1}}\right)$. Os resultados para o $\mathrm{Cu}^{2+}$ mostram que $\mathrm{CA}$ Bagaço adsorveu no equilíbrio $27,88 \mathrm{mg} \cdot \mathrm{g}^{-1}$, quantidade superior à adsorvida pelo CA Comercial (25,82 mg. $\left.\mathrm{g}^{-1}\right)$.

Como citado anteriormente, o $\mathrm{pH}$ inicial foi ajustado em 6 , e, como não foi possível monitorar o $\mathrm{pH}$ durante os ensaios, aferiu-se esses valores ao término de cada teste cinético. A Tabela 1 apresenta os valores de pH após os testes dos íons $\mathrm{Cd}^{2+}$ e $\mathrm{Cu}^{2+}$.

Tabela 1 - Valores de $\mathrm{pH}$ obtidos após os testes cinéticos com $\mathrm{Cd}^{2+} \mathrm{e} \mathrm{Cu}^{2+}$

\begin{tabular}{ccc}
\hline Ensaio (min) & $\mathrm{pH}$ final $\mathrm{Cd}^{2+}$ & $\mathrm{pH}$ final $\mathrm{Cu}^{2+}$ \\
\hline 10 & 5,81 & 5,81 \\
20 & 5,81 & 5,82 \\
30 & 5,83 & 5,81 \\
40 & 5,90 & 5,81 \\
50 & 5,83 & 5,80 \\
60 & 5,84 & 5,78 \\
360 & 5,70 & 5,65 \\
1440 & 5,10 & 5,31 \\
2880 & 5,93 & 5,68 \\
\hline
\end{tabular}

Fonte: Abreu (2013)

É possível perceber que há uma considerável variação do $\mathrm{pH}$ à medida que a adsorção ocorre. A diminuição do $\mathrm{pH}$ ao final dos testes cinéticos pode ser justificada com o mecanismo de troca iônica representado pelas Equações 3 e 4 . A adsorção dos íons metálicos na superfície do carvão ativado leva à liberação de $\mathrm{H}^{+}$e, consequentemente, acidificação da solução.

\subsection{Efeito do pH na Adsorção dos Íons Metálicos}

Os resultados dos experimentos realizados para determinação dos valores de pH ótimo para a remoção de $\mathrm{Cd}^{2+}$ e $\mathrm{Cu}^{2+}$ pelo CA Bagaço são mostrados na Figura 2. Para o metal cádmio, os ensaios foram conduzidos em $\mathrm{pH}$ variando entre 4 e 8 . Já para o cobre, há impossibilidade de se ajustar a solução para $\mathrm{pH}$ superior a 6 , devido à formação do precipitado $\mathrm{Cu}(\mathrm{OH})_{2}$. Dessa forma, para a remoção de $\mathrm{Cu}^{2+}$, o efeito do $\mathrm{pH}$ foi avaliado na faixa de $\mathrm{pH}$ entre 3 e 6 . 
Figura 2 - Efeito do pH na adsorção de $\mathrm{Cd}^{2+} \mathrm{e}$ $\mathrm{Cu}^{2+}$ sobre CA Bagaço

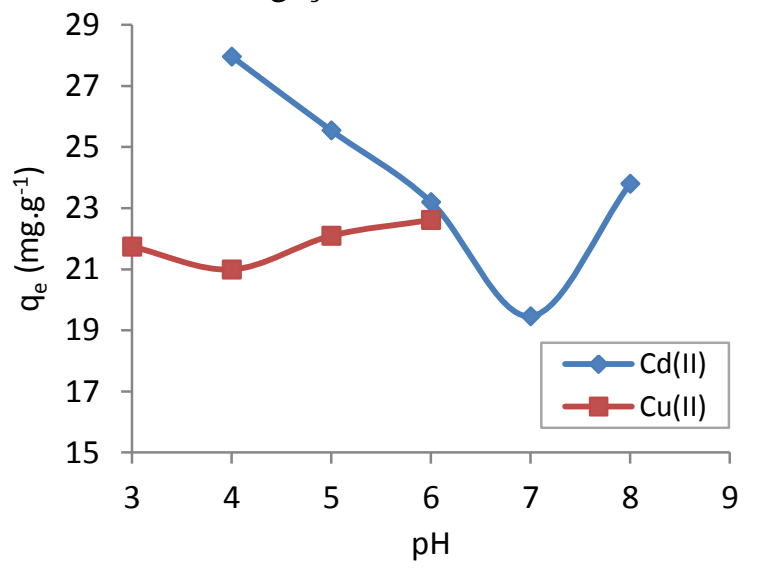

Fonte: Abreu (2013)

Como regra geral, para carvões ativados, o aumento do $\mathrm{pH}$ resulta no aumento do número de sítios de adsorção negativamente carregados e diminuição do número de sítios positivamente carregados dos carvões ativados, o que eleva à adsorção de cátions metálicos (KADIRVELU e NAMASIVAYAM, 2003). Sendo assim, os resultados do efeito do $\mathrm{pH}$ desse trabalho apresentados na Figura 2 são surpreendentes, especialmente para $\mathrm{o} \mathrm{Cd}^{2+}$, já que à medida que o pH aumenta tem-se diminuição da quantidade adsorvida. Uma explicação plausível para este comportamento pode ser a presença de grupos funcionais no CA Bagaço a serem identificados.

Ainda de acordo com a Figura 2, os valores de $\mathrm{pH}$ que promoveram a maior remoção dos íons metálicos foram 4 para o cádmio e 6 para o cobre. Mohan, Pittman Jr. e Steele (2006), obtiveram o valor de 4,5 como o pH ótimo para a adsorção tanto de $\mathrm{Cd}^{2+}$, quanto de $\mathrm{Cu}^{2+}$. Este valor é próximo ao determinado no presente estudo para o $\mathrm{Cd}^{2+}$ (4). Em relação cobre, resultado próximo ao do presente trabalho foi encontrado por Gurgel, de Freitas e Gil (2008), que obtiveram a capacidade ótima de remoção de $\mathrm{Cu}^{2+} \mathrm{em}$ $\mathrm{pH}$ igual a 5,6. Entretanto, estes mesmos autores determinaram $\mathrm{pH}$ igual a 6,1 para a adsorção de $\mathrm{Cd}^{2+}$. Este resultado se diferencia significativamente do presente estudo.

As diferenças de resultados na avaliação do efeito do $\mathrm{pH}$ na adsorção dos íons metálicos podem ser atribuída a fatores como: material adsorvente, quantidade de carvão e volume de solução utilizada no ensaio, ou ainda, pela impossibilidade de corrigir o $\mathrm{pH}$ durante o ensaio para que a quantidade de metal adsorvida permanecesse constante, como é feito por Goyal et al. (2001).

\subsection{Isotermas de Adsorção}

As isotermas de adsorção relacionam a quantidade $q_{e}$ de íons $\mathrm{Cd}^{2+}$ ou $\mathrm{Cu}^{2+}$ adsorvida e a concentração $C_{e}$ desses íons na fase líquida em equilíbrio determinadas experimentalmente. Estas isotermas experimentais podem ser ajustadas por modelos matemáticos que descrevem suas relações de equilíbrio. Neste trabalho, foram testados os modelos de Freundlich e Langmuir, que são modelos amplamente aceitos e facilmente linearizados (VOLESKY E HOLAN, 1995).

O modelo de Freundlich é empírico e, apesar ter sido o primeiro a ser proposto, a sua equação ainda é largamente empregada, tendo resultados satisfatórios na faixa de concentrações intermediárias (BRUNAUER, 1943). A equação de Freundlich não prevê um limite de adsorção, assim, a superfície pode receber uma cobertura infinita sem haver a saturação do adsorvente (THOMAS E CRITTENDEN, 1998). As Equações 5 e 6 apresentam a isoterma de Freundlich:

$$
\begin{aligned}
& q_{e}=k_{F} C_{e}^{1 / n} \quad \text { (forma não linear) } \\
& \log q_{e}=\log k_{F}+\frac{1}{n} \log C_{e} \\
& \text { (forma logarítmica linear) }
\end{aligned}
$$

nas quais $q_{e}$ é a quantidade adsorvida por grama de adsorvente, $C_{e}$ é a concentração do íon metálico em equilíbrio na fase líquida, e 
$k_{F}$ e $n$ são as constantes de Freundlich relacionadas à capacidade de adsorção e à intensidade de adsorção, respectivamente.

Os valores de $k_{F}$ e $n$ podem ser obtidos, respectivamente, a partir dos coeficientes linear e angular da plotagem da forma linearizada do modelo (Equação 6). Tem-se que a adsorção é favorável quando $n$ está na faixa de 1 a 10 (TEOH, KHAN e CHOONG, 2013).

O modelo de Langmuir assume, dentre outras hipóteses, a adsorção em monocamada molecular, energias de adsorção uniformes sobre a superfície e nenhuma interação entre moléculas adsorvidas e sítios vizinhos (RUTHVEN, 1984). A isoterma de Langmuir é dada pelas Equações 7 e 8:

$q_{e}=\frac{q_{m} k_{L} C_{e}}{1+k_{L} C_{e}} \quad$ (forma não linear)

$\frac{C_{e}}{q_{e}}=\frac{1}{k_{L} q_{m}}+\frac{C_{e}}{q_{m}} \quad$ (forma linear)

nas quais $q_{m}$ é a capacidade máxima de adsorção e $k_{L}$ é a constante de Langmuir relacionada à energia de adsorção (TEOH, KHAN e CHOONG, 2013).

Valores de $q_{m}$ e $k_{L}$ podem ser calculados a partir da inclinação e da interseção da plotagem da Equação 8 linear $\left(C_{e} / q_{e}\right.$ versus $\left.C_{e}\right)$.

A característica essencial da isoterma de Langmuir pode ser expressa como uma constante adimensional, conhecida como fator de separação, $R_{L}$, dado pela Equação 9:

$R_{L}=\frac{1}{1+k_{L} C_{0}}$

em que $k_{L}$ é a constante de Langmuir, $C_{0}$ é a concentração inicial da solução e $R_{L}$ indica o formato da isoterma: desfavorável se $R_{L}>1$; linear se $R_{L}=1$; favorável se $0<R_{L}<1$; e irreversível se $R_{L}=0$ (MOHAN, PITTMAN JR. e STEELE, 2006).
A Figura 3 apresenta as isotermas de Freundlich e de Langmuir para a adsorção de $\mathrm{Cd}^{2+}$ e $\mathrm{Cu}^{2+}$ pelo $\mathrm{CA}$ Bagaço a $30{ }^{\circ} \mathrm{C}$. $\mathrm{Na}$ Tabela 2, se tem os parâmetros dessas isotermas, bem como os coeficientes de correlação $\left(R^{2}\right)$ de seus ajustes lineares.

Figura 3 - Isotermas de adsorção de: (a) $\mathrm{Cd}^{2+} \mathrm{e}$ (b) $\mathrm{Cu}^{2+}$. Linhas tracejadas: ajustes pelo modelo de Langmuir. Linhas sólidas: ajustes pelo modelo de Freundlich
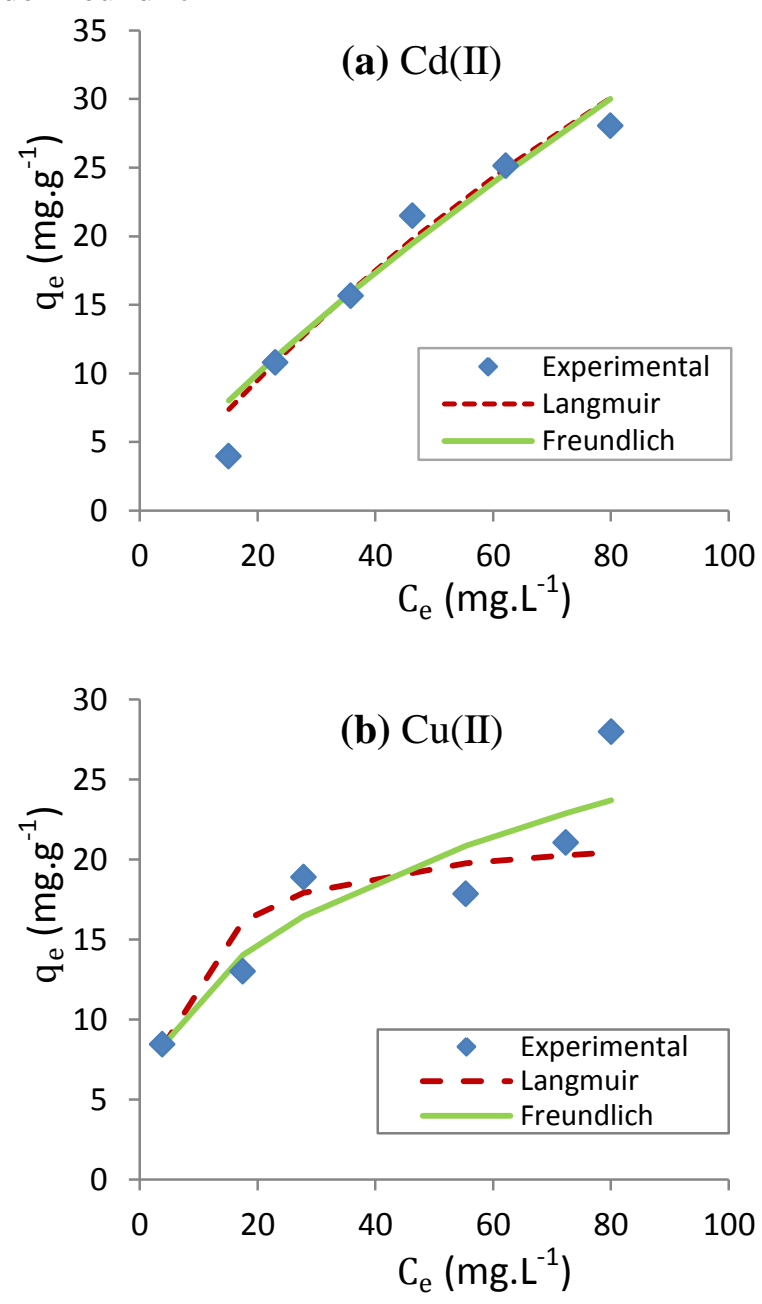

Fonte: Autor (2015) 


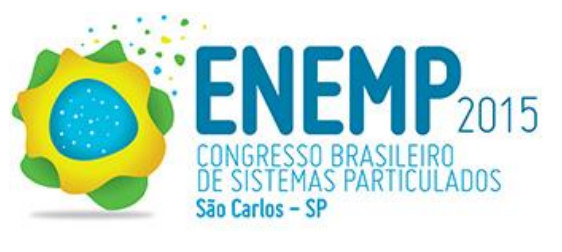

Tabela 2 - Parâmetros dos modelos de Freundlich e Langmuir para cádmio e cobre

\begin{tabular}{llcc}
\hline Modelo & & $\mathrm{Cd}^{2+}$ & $\mathrm{Cu}^{2+}$ \\
\hline \multirow{4}{*}{ Freundlich } & $n(-)$ & 1,263 & 2,906 \\
& $k_{F}\left(\mathrm{mg} \cdot \mathrm{g}^{-1}\right)$ & 0,935 & 5,240 \\
& $R^{2}(-)$ & 0,973 & 0,903 \\
\hline \multirow{4}{*}{ Langmuir } & $q_{m}\left(\mathrm{mg}^{-1}\right)$ & 106,383 & 22,075 \\
& $k_{L}\left(\mathrm{~L} \cdot \mathrm{g}^{-1}\right)$ & 0,005 & 0,155 \\
& $R^{2}(-)$ & 0,989 & 0,898 \\
\hline
\end{tabular}

Fonte: Autor (2015)

A análise visual da Figura 3(a) indica que ambos os modelos de Langmuir e de Freundlich ajustaram bem os dados de adsorção de $\mathrm{Cd}^{2+}$ no equilíbrio. Entretanto, através dos resultados da Tabela 2, a comparação dos valores de $R^{2}$ para os modelos de Freundlich e Langmuir indica que a equação de Langmuir oferece uma correlação melhor para os dados experimentais de adsorção de $\mathrm{Cd}^{2+}$ no equilíbrio. A capacidade máxima, $q_{m}$, de remoção de $\mathrm{Cd}^{2+}$ fornecida pelo modelo de Langmuir foi $106,383 \mathrm{mg} \cdot \mathrm{g}^{-1}$. Karnitz et al. (2007) obtiveram capacidade máxima de adsorção de $196 \mathrm{mg} \cdot \mathrm{g}^{-1}$ empregando bagaço de cana-de-açúcar modificado como adsorvente. Já Mohan e Singh (2002), usando carvão de bagaço como adsorvente, obtiveram a capacidade bem menor de 38,03 mg. ${ }^{-1}$ para a remoção de $\mathrm{Cd}^{2+}$.

Pelo modelo de Langmuir e considerando que a concentração máxima inicial avaliada foi de $150 \mathrm{mg} . \mathrm{L}^{-1}$, o fator de separação foi $R_{L}=0,5748$, confirmando a adsorção favorável dos íons $\mathrm{Cd}^{2+}$ sobre o CA Bagaço. A hipótese básica da isoterma de Langmuir baseia-se na cobertura em monocamada na superfície do adsorvente, o que indica que a adsorção de íons $\mathrm{Cd}^{2+}$ sobre a superfície do adsorvente gera a formação de uma monocamada.

Por outro lado, para os íons $\mathrm{Cu}^{2+}$, os valores de $R^{2}$ obtidos em ambos os modelos de Freundlich e de Langmuir foram baixos (em torno de 0,90). Visualmente, a Figura 3(b) confirma estes ajustes ruins, que podem estar associados às hipóteses simplificativas inerentes aos modelos. O modelo de Freundlich tem como principal restrição o fato de não prever a saturação dos sítios. $O$ modelo de Langmuir, por sua vez, considera que os sítios de ligação são distribuídos homogeneamente na superfície do adsorvente, assumindo que não existe interação entre as moléculas do adsorvente. O que na prática dos testes de adsorção não acontece.

\section{CONSIDERAÇÕES FINAIS}

Este trabalho demonstra que o carvão de bagaço de cana-de-açúcar e ativado com cloreto de zinco constitui um potencial adsorvente alternativo para o tratamento de efluentes contendo íons cádmio e cobre.

A caracterização do carvão ativado de bagaço de cana mostrou que seu pH é de 4,62, sendo então um material de propriedade ácida e apto à adsorção de íons metálicos.

Através de testes cinéticos, determinouse o tempo de equilíbrio como de $48 \mathrm{~h}$ para a adsorção dos íons $\mathrm{Cd}^{2+}$ e $\mathrm{Cu}^{2+}$.

A comparação do carvão ativado produzido a partir de bagaço e do carvão ativado comercial granular mostrou que suas capacidades de adsorção no equilíbrio são muito similares se tratando do $\mathrm{Cd}^{2+}$. Em relação ao $\mathrm{Cu}^{2+}$, a quantidade adsorvida pelo carvão ativado de bagaço no equilíbrio é superior à adsorvida pelo comercial.

A avaliação do efeito do $\mathrm{pH}$ mostrou que o melhor $\mathrm{pH}$ a adsorção ocorre próximo de 4 para o $\mathrm{Cd}^{2+}$ e próximo de 6 para o $\mathrm{Cu}^{2+}$.

$\mathrm{O}$ modelo de Langmuir forneceu a melhor correlação dos dados experimentais de equilíbrio para a remoção de $\mathrm{Cd}^{2+}$. Neste caso, a isoterma é favorável e a capacidade máxima do carvão ativado de cana foi determinada como $196 \mathrm{mg} \cdot \mathrm{g}^{-1}$.

Demonstrou-se que o bagaço de canade-açúcar, material residual disponível em grande quantidade no Brasil, pode ser usado 
no tratamento de efluentes contaminados com metais pesados. Na forma de carvão ativado, o bagaço mostrou-se eficaz na remoção dos íons $\mathrm{Cd}^{2+} \mathrm{e} \mathrm{Cu}^{2+}$.

Sugerem-se estudos complementares envolvendo, por exemplo, determinação de parâmetros cinéticos e ensaios de remoção dos metais em leito fixo empregando o carvão ativado de bagaço de cana-de-açúcar como adsorvente.

\section{NOMENCLATURA}

\section{$q_{t}$}

Capacidade de adsorção em

determinado tempo $t$

mg. $g^{-1}$

Capacidade de adsorção no $\mathrm{mg} \cdot \mathrm{g}^{-1}$

$q_{e}$ equilíbrio

Capacidade máxima de $\mathrm{mg}_{\text {adsorção }}{ }^{-1}$
Coñ

$9 m$ adsorção

$C_{t} \begin{aligned} & \text { Concentração de adsorbato na } \\ & \text { fase líquida a dado tempo } t\end{aligned} \quad \mathrm{mg} . \mathrm{L}^{-1}$

Concentração de adsorbato na $\mathrm{mg} . \mathrm{L}^{-1}$

$C_{e}$ fase líquida em equilíbrio

$C_{0} \begin{aligned} & \begin{array}{l}\text { Concentração inicial } \\ \text { adsorbato na fase líquida }\end{array} \\ & \text { Ce } \quad \mathrm{mg} . \mathrm{L}^{-1}\end{aligned}$

$k_{F}$ Constante de Freundlich $\quad$ L.g ${ }^{-1}$

$k_{L} \quad$ Constante de Langmuir $\quad \mathrm{L}_{\mathrm{g}} \mathrm{g}^{-1}$

$n$ Fator de heterogeneidade de (-)

$R_{L} \quad$ Fator de separação

$m$ Massa de adsorvente g

$V$ Volume de solução L

\section{REFERÊNCIAS}

ABREU, M. B. Preparação de carvão ativado de bagaço de cana-de-açúcar e sua aplicação na adsorção de $\mathrm{Cd}$ (II) e $\mathrm{Cu}$ (II). 2013. 52p. Monografia (Curso Superior em Tecnologia em Processos Químicos) Universidade Tecnológica Federal do Paraná, Apucarana, 2013.

BRASIL. Companhia Nacional de Abastecimento. Acompanhamento da safra brasileira de cana-de-açúcar, v.1 - safra
2014/15, n.4 - quarto levantamento. Brasília, DF, abr. de 2015. Disponível em: <http://www.conab.gov.br>. Acesso em: 10 jun. 2015.

BRUNAUER, S. The Adsorption of Gases and Vapors. In: Physical Adsorption. London: Humphrey Milford, 1943.

GOYAL, M.; RATTAN, V. K.; AGGARWAL, D.; BANSAL, R. C. Removal of copper from aqueous solutions by adsorption on activated carbons. Colloids and Surfaces A: Physicochemical and Engineering Aspects, v.190, p.229-238, 2001.

GUPTA, V. K., ALI, I. Removal of lead and chromium from wastewater using bagasse fly ash-a sugar industry waste. Journal of Colloid and Interfacial Science, v.271, p.321-328, 2004.

GURGEL, L. V. A.; DE FREITAS, R. P.; GIL, L. F. Adsorption of $\mathrm{Cu}(\mathrm{II}), \mathrm{Cd}(\mathrm{II})$, and $\mathrm{Pb}$ (II) from aqueous single metal solutions by sugarcane bagasse and mercerized sugarcane bagasse chemically modified with succinic anhydride. Carbohydrate Polymers, v.74, p.922-929, 2008.

JAIN, M.; GARG, V. K.; KADIRVELU, K. Cadmium(II) sorption and desorption in a fixed bed column using sunflower waste carbon calcium-alginate beads. Bioresource Technology, v.129, p.242-248, 2013.

KADIRVELU, K; NAMASIVAYAM, C. Activated carbon from coconut coirpith as metal adsorbent: adsorption of $\mathrm{Cd}(\mathrm{II})$ from aqueous solution. Advances in Environmental Research, v.7, p.471-478, 2003.

KARNITZ, O. JR.; GURGEL, L. V. A.; DE FREITAS, R. P.; GIL, L. F. Adsorption of $\mathrm{Cu}(\mathrm{II}), \mathrm{Cd}(\mathrm{II})$, and $\mathrm{Pb}$ (II) from aqueous single 
metal solutions by mercerized cellulose and mercerized sugarcane bagasse chemically modified with EDTA dianhydride (EDTAD). Carbohydrate Polymers, v.77, p.643-650, 2009.

KARNITZ，O. JR.; GURGEL，L. V. A.; PERIN DE MELO, J. C.; BOTARO, V. R.; MELO, T. M. S.; GIL, R. P. F. Adsorption of heavy metal ion from aqueous single metal solution by chemically modified sugarcane bagasse. Bioresource Technology, v.98, p.1291-1297, 2007.

MOHAN, D.; PITTMAN JR., C. U.; STEELE, P. H. Single, binary and multicomponent adsorption of copper and cadmium from aqueous solutions on Kraft lignin - a biosorbent. Journal of Colloid and Interface Science, v.297, p.489-504, 2006.

MOHAN, D.; SINGH, K.P. Single- and multi-component adsorption of cadmium and zinc using activated carbon derived from bagasse - an agricultural waste. Water Research, v.36, 2304, 2002.

RUTHVEN, D. M. Principals of Adsorption and Adsorption Processes. New York: John Wiley \& Sons, 1984.

SCHETTINO JR., M. A. Ativação química do carvão de casca de arroz utilizando NaOH. 2004. 78p. Dissertação (Mestrado em Física) - Universidade Federal do Espírito Santo, Vitória, 2004.

SING, K. S. W. et al. Reporting physisorption data for gas/solid systems with special reference to the determination of surface area and porosity (Recommendations 1984). Pure and Applied Chemistry, v.57, n.4, p.603619, 1985.
SUZUKI, M. Adsorption Engineering. In: Chemical Engineering Monographs. v. 25. Japan: Kodansha, 1990.

TEOH, Y. P.; KHAN, M. A., CHOONG, T. S. Y. Kinetic and isotherm studies for lead adsorption from aqueous phase on carbon coated monolith. Chemical Engineering Journal, v.217, p.248-255, 2013.

THOMAS, W. J.; CRITTENDEN, B. D. Adsorption Technology and Design. Lymington: Butterworth-Heinemann, 1998.

ÜÇER, A.; UYANIK, A.; ÇAY, S; ÖZKAN, Y. Immobilisation of tannic acid onto activated carbon to improve $\mathrm{Fe}(\mathrm{III})$ adsorption. Separation and Purification Technology, v.44, p.11-17, 2005.

VALIX, M.; CHEUNG, W. H.; MCKAY, G. Preparation of activated carbon using low temperature carbonisation and physical activation of high ash raw bagasse for acid dye adsorption. Chemosphere, v.56, p.493501, 2004.

VOLESKY, B.; HOLAN, Z. R. Biosorption of heavy metals. Biotechnology Progress, v.11, p.235-251, 1995. 